\title{
44157 - IS KETAMINE EFFECTIVE IN POSTTONSILLECTOMY PAIN IN CHILDREN?
}

\author{
Ibrahim Abu-Shahwan, Children Hospital of Eastern Ontario, Ottawa, ON, Canada; \\ Khalid Chowdary, Children Hospital of Eastern Ontario; \\ Kimmo Murto, Children Hospital of Eastern Ontario; \\ Uwe Schwarz, Children Hospital of Eastern Ontario; \\ Christine Lamontagne, Children Hospital of Eastern Ontario;
}

Introduction: Tonsillectomy is a common surgical procedure in childhood. It is associated with moderate to severe pain. About $20 \%$ of children undergoing routine adenotonsillectomy had significant sleep apnea and $2 \%$ had obstructive apnea syndrome (1). Effective and safe analgesia without respiratory and airway compromise can be challenging in these patients. The aim of this prospective, randomized, double blind study was to evaluate the effect of ketamine on postoperative analgesia and opioid consumption in children undergoing tonsillectomy.

Methods: After ethics committee and parents/guardian approval we evaluated the efficacy of subhypnotic doses of ketamine on postoperative morphine consumption in 84 children 2- 12 years of age, ASA I-III undergoing elective tonsillectomy with or without adenoidectomy. Oral acetaminophen $30 \mathrm{mg} / \mathrm{kg}$ (max. dose of 1300mg) was given $30 \mathrm{~min}$. before the start of surgery to all children. Patients were divided into two groups. After induction of anesthesia children in Group I were given morphine $0.1 \mathrm{mg} / \mathrm{kg}$ and children in Group II were given morphine 0.1 $\mathrm{mg} / \mathrm{kg}$ and ketamine $0.25 \mathrm{mg} / \mathrm{kg}$. One way analysis of variance (ANOVA) and chi-square test were used for statistical analysis.

Results: children completed the study. There were 43 children in the ketamine group. Two children were excluded from each group because of incomplete information. There were no significant differences in age, sex, weight, ASA status, and duration of the surgical procedure or anesthesia between the two groups. There was no statistically significant difference in time to eye opening, recovery room discharge time, postoperative hospital stay, and vomiting between the two groups. 32 patients in the placebo group and 24 patients in the ketamine group required morphine in the recovery room. The day after surgery, 31 children in the morphine group and 27 children in the ketamine group complained of pain. There were no episodes of hallucinations or bad dreams in the ketamine group.

Discussion: Preemptive analgesia is used to reduce or prevent the development of pain memory and to decrease postoperative analgesic requirement. Ketamine is a potent NMDA receptor antagonist that may reduce the amount of analgesics required in the postoperative period (2). The results of this study show that the addition of intravenous ketamine, $0.25 \mathrm{mg} / \mathrm{kg}$, before the start of surgery, was not effective in reducing postoperative morphine consumption in children undergoing tonsillectomy. 
References: 1- Clin Otolaryngol 1990; 15: 307-314.

2- Anesth-Analg 1997; 5: 1086-1091. 